\title{
Enhancing Critical Thinking Skill Formation: Getting Fast Thinkers to Slow Down ${ }^{1}$
}

\author{
John A. List \\ University of Chicago and NBER
}

January 2021

\begin{abstract}
In the past several decades academics and policymakers have grappled with how to augment the traditional classroom approach to enhance critical thinking skill formation. In this note, I take a different approach. I begin by developing a Critical Thinking Hierarchy, where from the bottom of the hierarchy upwards two key skills evolve: developing/assimilating empirical evidence to update one's beliefs (connecting the dots with empiricism) and putting the puzzle pieces together with conceptual reasoning (connecting the dots with abstract thought). Skills lower down in the hierarchy must be achieved before individuals can gain skills higher up. A key aspect of the CT skill formation process revolves around student's maturation from "fast thinking" to "slow thinking". My overall approach is useful because it at once defines critical thinking, pinpoints where improvements must be made for development, and provides a classroom playbook to enhance critical thinking skill formation.
\end{abstract}

Keywords: critical thinking skill formation, hierarchy, fast and slow thinking JEL Codes:

\footnotetext{
${ }^{1}$ Thanks to David Franks, Uditi Karna, Ariel Listo, and Lina Ramirez for providing excellent research assistance. This paper was created as a constructive comment on the study of John Siegfried and David Colander, "What does critical thinking mean in teaching economics, the big and little of it" (2021).
} 


\section{Introduction}

Soon after I was dispatched to discuss the important work of John Siegfried and David Colander (2021), I asked 30 people to define critical thinking. I received 25 different answers. When I asked those same 30 people if critical thinking (CT) is important in life, I received 1 answer: YES! Using my own CT skills, I then reasoned that in the area of CT skill formation, we seem to agree that what we do not homogeneously define is nevertheless important in life. In this spirit, CT is akin to creativity, great intuition, and deep insights, meaningful characteristics of scholars that we might find difficult to define precisely but we know them when we see them; and we very much appreciate them.

In my own experiences in both the classroom and in my travels, I have come to define the key aspects of CT as individual skills that facilitate logical and informed decisions. I have observed the import of such skills in nearly every walk of life-from watching Greg Mankiw use his own CT skills to urge President Bush to adopt a carbon tax when we were in the White House together, to my own use of CT in the last 25 years partnering with organizations as varied as Lyft (a ride-share company) and Smile Train (a non-profit fixing cleft palates of young children) to convince them of the value of field experimentation. In each, and related situations, observing how organizations arrive at solutions has taught me that central to most, if not all, of these cases is CT skills. Beyond personal anecdotes, scientifically the import of CT has been shown in many walks of life (see, e.g., Bauwens and Gerhard, 1987).

Nevertheless, the literature and our own experiences as teachers reveal that few students naturally supply CT, and it is costly for them to do so, hence if we do not demand it students will not supply it. Yet, as teachers, it is important to first understand what "it" is-what is CT? If we don't know what it is then how can we teach it? As John and David rightly point out, CT has a variety of interpretations. My preferred definition is provided above, and that is where my modeling ideas begin.

In my own experiences, these skills can naturally be divided into two complementary pillars:

- Connecting the dots with empiricism: developing and assimilating empirical evidence and updating of one's beliefs

- Connecting the dots with abstract thought: putting the puzzle together with conceptual reasoning; thought experiments 
With these in mind, I conjecture that CT skill formation occurs in stages, or as a "Critical Thinking Hierarchy," in a Maslowian progression spirit, but with a distinct flavor of the seminal work due to Elder and Paul $(1996 ; 2010){ }^{2}$

In this spirit, humans cognitive development is characterized by a hierarchy of CT skill formation. Skills are organized in a hierarchy of prepotency in which more basic skills must be learned prior to higher skill formation. My model asserts that when a skill is formed it will become habit, and the mind re-allocates mental activities towards meeting the next level on the CT Hierarchy. Those then become the means of CT growth. Importantly, growth needs do not stem from a lack of something, but rather from a desire to grow as a person. These are what we, as teachers, must cultivate and embolden in our classroom instruction because they are costly to provide for the student. In our absence, they would not provide CT. Through the framework, once CT skills are formed and progression up the hierarchy occurs, the student may be able to reach the highest level, which I denote as the "The Great Thinker."

Within both of these pillars lies the heart of the problem, which can be better understood and solved with economic thinking. To begin, as aforementioned, it is key to understand that CT is costly. Because of this, the human mind tends to apply heuristics ("fast thinking") since most of the time those work well enough, and they are much less effortful ("cheaper") than "slow thinking". The unfortunate aspect of this human tendency is that in many cases cognitive biases creep into decisionmaking, leading to misapplied heuristics and incorrect reasoning. My solution, therefore, revolves around the notion that since CT is generally "slow" (i.e. "expensive"), the key to moving up the hierarchy is inducing students to habitually think "slowly," which effectively reduces the cognitive costs of "thinking slow". Indeed, there is psychological research that suggests there exists preferences over thinking (see Cacioppo and Petty (1982) and the research that it set in motion), and if malleable the CT progression is naturally set in motion.

Leveraging this type of economic thinking, after presenting the CT Hierarchy and showing evidence that such skills are malleable, I then provide a classroom playbook for Principles of Economics instructors who desire to give their students the best chance to become Great Thinkers,

\footnotetext{
2 Psychologist Abraham Maslow $(1943,1954)$ theorized that human motivation is based on people seeking fulfillment and change through personal growth. Self-actualized people are those who were fulfilled and doing all they were capable of.
} 
or at least progress into the upper echelons of the CT Hierarchy during and after their course. I conclude with some remarks drawing parallels between what we have learned from introducing behavioral economics into the standard Principles course that can inform us about introducing CT.

\section{A Critical Thinking Hierarchy}

To teach the species we must understand the species. For our purposes, therefore, we must first define CT. There is no right or wrong here, just preferences. My travels have informed my own impressions about which CT skills lend themselves to success beyond the classroom and those skills can naturally be divided into two pillars: one "concrete" and one "abstract". The concrete pillar is how we connect the dots with empiricism. This starts with gathering, developing, and assimilating empirical evidence and ends with how one updates her beliefs. This path, however simple it sounds, is steeped with potholes that most students cannot navigate alone.

This is because strong behavioral biases permeate every step of "fast thinking" (see Kahneman, 2011). First, when gathering data, confirmation bias prohibits most students from generating an optimal mixture of acquired information. That is, humans have a strong tendency to search for information that they believe will confirm their prior beliefs, or closely held views. Second, even if this information collecting bias is overcome, there might be a tendency to interpret, weight, and recall information in a way that conforms to causal fallacy - the "easy" or "least costly" way to interpret data.

For example, let's assume that the student can overcome confirmation bias when collecting, weighting, and recalling new acquired information. The student is then at the stage of how to understand the nature of the received empirical evidence-what it means and how to update beliefs. At this point, any instructor who has ever taught correlation versus causation understands what I am arguing here. For instance, when observing a positive correlation between ice cream cone consumption and drowning deaths, a student quickly presumes that one should not take a swim after consuming ice cream (see Gneezy and List, 2013). Or, upon learning that cows named Buttercup produce more milk, they might urge local farmers to name all of their cows Buttercup. ${ }^{3}$

\footnotetext{
${ }^{3}$ In a survey of 516 UK farmers, Bertenshaw and Rowlinson (2009) found that farmers who named their dairy cattle improved their overall milk yield by almost 500 pints (284 liters) annually. When it was published this result caught the attention of the media, which popularized these findings adding common cow names such as Buttercup and Daisy. Bertenshaw and Rowlinson (2009) did not test the qualities of particular names, but they did find that giving a name and befriending an animal cut its levels of cortisol, a stress hormone known to inhibit milk production.
} 
Both errors are made because of fast thinking that induces CT flaws - not understanding that a third variable lurks behind both correlations - hot weather in the first and extra attention and love in the second.

Even after mastering causal inference, the student remains with the task of updating their beliefs appropriately. Here, the "fast thinking" cognitive behavioral biases arise again, with the nature of humans anchoring and falling prey to status quo bias, not updating their priors enough in the face of new empirical evidence (see Alevy et al., 2007). That is, even in the face of new evidence, students tend to hold dearly to their initial priors and stubbornly update, because doing so is costly. This is found across various parts of the economy, as shown in Alevy et al. (2007) and the citations therein. Yet, advanced thinkers are able to overcome these biases, and when interpreting empirical results, they understand how to generalize appropriately across populations of people and situations. In a nutshell, working through the CT Hierarchy allows the student to better connect the dots through empiricism.

Of course, CT revolves around more than empiricism, or tasks of a "concrete" nature. The second camp of CT skill formation is learning to connect the dots with abstract thought; that is, putting the puzzle together with conceptual reasoning and thought experiments. Clearly, this pillar and the first pillar have much in common developmentally, and likely arise in a concomitant manner because of the fast thinking nature of people. A key feature within this pillar over the CT Hierarchy is recognition and adjusting for egocentrism, both in self and when understanding the behavior of others. Furthermore, eliminating key cognitive biases that arise naturally in humans is a key developmental feature in this camp.

Within much of economics training, the inability to understand another person's point of view leads to natural confusion and frustration for the student. Viewing the world exclusively through one's own eyes is a natural tendency for a fast thinker, but it limits CT skills in fundamental ways and curbs growth through the CT Hierarchy. For example, when reasoning how a competitor in game theory will play the prisoner's dilemma, the advanced thinker begins to wonder: does the other player have an incentive to deviate? Importantly, this question must be understood to reason correctly, and to understand the equilibrium of the game. These general features are mimicked throughout the economy, from oligopolies, to lobbying, to interpreting received research, to understanding interactive environments more broadly. 
As CT advancement occurs, thinking slows down and more consistent applications in thought regarding fairness, ignorance, and prejudice, begin to arise, both in evaluating self and others. Likewise, intellectual humility, empathy, and courage in one's CT skills allow the student to think through more complex problems. Moreover, such development opens up deeper and more rewarding communications with others that begin to allow partnerships to be more constructive. With this slower thinking, a level of curiosity evolves in CT over the hierarchy that helps the advanced thinkers begin to question their own wisdom and thought processes, and at this stage attributional biases and theory of mind deficiencies are attenuated. For instance, correspondence bias begins to take a back seat to more rational interpretations of situations and evaluations of people and entities. In the limit, the great thinkers do not mind, and even appreciate, intellectual confrontation because they are their worst critic.

\subsection{Critical Thinking Hierarchy}

To provide an ocular depiction of what I have in mind, I create Figure 1, which places the above descriptions of the evolution of CT skills into a hierarchy. My goal in doing so is to leverage the insights from the psychology of education literature to provide a succinct summary of how empiricism and abstract reasoning evolves, and where we can step in as teachers to make an impact.

\section{Figure 1: Critical Thinking Hierarchy}

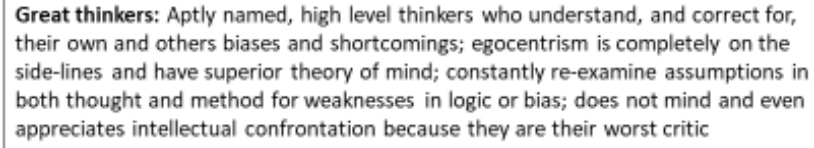

Great thinkers: Aptly named, high level thinkers who understand, and correct for, their own and others biases and shortcomings; egocentrism is completely on the side-lines and have superior theory of mind; constantly re-examine assumptions in both thought and method for weaknesses in logic or bias; does not mind and even appreciates intellectual confrontation because they are their worst critic

Adept thinkers: Begin to critically question; understand their own thinking has blind spots and develop skills to address them; put most of egocentrism on the sidelines; understand causation and various cognitive biases and tries to avoid them; understands theory of mind but makes some mistakes in its application. Seeks to improve their own theory of mind and research prowess

Neophyte thinkers: Understand the import of thinking, yet they question little but most obvious inconsistencies; begin to appreciate the value of empiricism but often confuse correlation for causation; remain largely egocentric, subject to various research and thought biases, have little or no theory of mind.

Modal thinker: Choices and opinions based on preconceptions, prejudices, not based on reason or facts. Biases permeate their research and updating of beliefs (status quo bias, confirmation bias, etc.) as they readily accept what conforms to their

misconceptions without question. Argument is by example

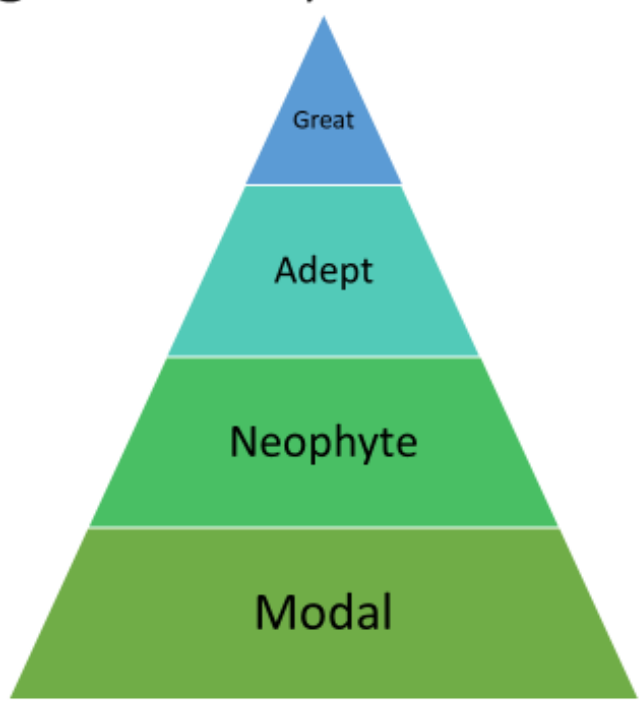


Starting at the base of Figure 1, for "Modal Thinkers" speed in thinking rules the day. Egocentrism is ubiquitous, various biases permeate their development of evidence and updating of beliefs (status quo bias, confirmation bias, correspondence bias, etc., are all unchecked in their reasoning). Modal Thinkers readily accept what conforms to their misconceptions without question (free trade is bad because I read it on the internet and my uncle lost his job because of free trade), and their preferred mode of argument tends to be by example because this approach is the least costly. I denote this type of thinker as "Modal" to follow the spirit of Elder and Paul (1996; 2010), who argue that most people fall within such CT characterizations of their own. Indeed, in my own teachings and partnerships in the field, I find many beginning students falling into this part of the hierarchy, but very few leaders in the business and policy worlds occupy this space.

With improvements in CT skills, the student advances next to becoming a "Neophyte Thinker," which is a name to denote that this type of person is new to using CT skills. Such individuals understand the import of thinking, yet they question little but the most obvious inconsistencies in their own thought and reasoning as well as in others' thoughts and reasoning. They never question the integrity of data, or whether the purveyor of knowledge has an incentive to deliver such information. Neophyte Thinkers begin to appreciate the value of empiricism but often confuse correlation for causation. Conceptually, they remain largely egocentric, subject to various research and thought biases, and have little or no theory of mind. This is both because it does not come naturally to them, and it is very costly to provide. For instance, "Name all of your cows Buttercup because then they will produce more milk" is an example of faulty Neophyte reasoning.

Neophytes also lack important curiosity. Consider this: how many times have your students asked you for the empirical evidence behind the most basic predictions of the supply and demand model? I have taught Principles of Economics since 1994-from the University of Wyoming, University of Central Florida, University of Arizona, University of Maryland, University of Chicago, to Harvard (summer school) — and I practically beg students every time to ask me for the empirical evidence beyond this bread and butter aspect of neoclassical economics. Only after a few minutes of begging do I ever receive what I want - a show of curiosity, to which I can show them the Vernon Smith lab work (Smith, 1962) or the field results in List (2004).

The next level of thinker is the "Adept Thinker." Such thinkers begin to critically question; they understand their own thinking has blind spots and they develop skills to address them. The 
Adept Thinker puts most of egocentrism on the sidelines, he understands causation and various cognitive biases and tries to avoid them actively. He understands theory of mind but makes some mistakes in its application. When considering data and what we can learn, he knows whether to generalize empirical results across populations of people and situations, but the rules might not be uniformly applied.

The Adept Thinker might muse "I read the study that said cows named Buttercup produce more milk, and I reasoned that the mediator was the extra attention and love paid to that cow...this gives another reason why we should all be nice to animals." Adept thinkers not only understand their own flaws in reasoning but can spot the prejudices in others' points of view: will that policy or idea scale? Does that person have an incentive to say it will scale? The Adept Thinker seeks to improve their own theory of mind and research prowess but does not quite have the tools for perfection.

Finally, at the top of the CT Hierarchy is the aptly named, "Great Thinker". She is a high-level thinker who understands, and corrects for, her own and others biases and shortcomings. She places egocentrism completely on the side-lines and has superior theory of mind. She constantly reexamines assumptions in both thought and method for weaknesses in logic or bias. She does not mind, and even appreciates, intellectual confrontation because she is her own worst critic. She embodies what we all hope to become, a "slow thinker" who has come to it habitually.

\subsection{Are such CT Skills Mutable?}

If you have made it this far, you might astutely ponder: these characteristics all make sense to me, but are such skills even mutable? And, if so, how and in what kind of timeframe should I realistically expect to move them?

To the first question, the short answer is yes. A meta-analysis due to Abrami et al. (2015) found small (Hedges's $g$ - .3) but positive and statistically significant effect sizes for interventions intended to teach CT skills to students from grammar school to undergraduates. The average effect size for graduate students was, sadly, not statistically significant.

Concerning the second question, consider recent experiments performed by Stanford's Department of Physics and Graduate School of Education demonstrate that undergrads in an introductory physics lab instructed to think more critically with empirical evidence do so and, amazingly, results remained a year later, with students scattered across different classes (Holmes, 
Wieman, and Bonn 2015). Similarly, several other studies conducted experiments in which high school or undergraduate students are randomized into various teaching strategies designed to enhance higher order thinking skills and consistently find that those randomized into one of the treatment groups display significant improvements on several components of CT skills (see Miri, David, and Uri 2007, and Angeli and Valanides 2009). Terenzeni et al. (1995) document the effects of three dimensions of a student's college experience on CT skills and find evidence in support of both academic and nonacademic experiences jointly influencing CT development positively.

To consider evidence from the abstract camp, I hone in on but one example, theory of mind. The literature reports that such reasoning can also be learned, and even at a very young age, as we have evidence around theory of mind as early as 3-5 year old children (Charness et al. 2019 \& Cowell et al. 2015). With instruction, improvements in abstract reasoning skills can be had by children after a school year (Klauer 1999), undergraduates after a semester of formal instruction (Leighton 2006), and even people with traumatic brain injuries-after a few months of rehabilitation they can make gains that persist for years (Vas et al. 2016, Vas et al. 2011, Fath 2010).

\section{A Classroom Playbook: Getting Fast Thinkers to Slow Down}

Every student is capable and has the desire to move up the CT Hierarchy toward a level of Great Thinking, yet progress is often disrupted by our own failure of understanding that lower levels of CT needs must be met to progress. Indeed, most students are unaware of their own thinking patterns and do not have a structured reasoning approach well understood, rendering any student level "fixing" impossible. For example, the Economics Professor who hopes to teach how one can empirically identify demand and supply curves must surely be teaching students who understand the difference between correlation and causality. And, if the student is having conceptual difficulties, it must be the teacher diagnosing, being aware of the problem, and in turn fixing it. As teachers, our job is to give the student the best chance to move through the hierarchy in a uni-directional manner and provide them the tools to continue to do so after they leave the comforts of our classroom.

A key consideration, therefore, revolves around what we can do in the classroom to give students their best chance to become Great Thinkers, or at least progress into the upper echelons 
of the CT Hierarchy during and after our courses. Indeed, as advocates of CT skill formation, we should view our teaching as laying the foundation for not only growth within the classroom, but a playbook that the student can use for years after they leave our course. To achieve this goal, and maintain congruency with the CT Hierarchy, our teaching should help the student discover their own thinking and provide them with the tools to make a commitment intellectually to grow through the hierarchy.

With those goals in mind, a key consideration is why most students cannot come to achieving them on their own. My theory leverages basic economics to argue that applying heuristics ("fast thinking") works well enough in most cases, making more effortful "slow thinking" not worth it. The economic and psychological roots of this idea go back decades, and Kahneman scribed of its import in his 2011 popular book "Thinking Fast and Slow." The unfortunate aspect of this human tendency is that in many cases cognitive biases creep into decisionmaking, so if we are not able to habitually think slowly, we will find it difficult to move up the CT Hierarchy if left to our own vices. Modal thinking will result.

For these purposes, the design of the course content to promote CT skill formation should revolve around inducing students to constantly "slow think" and proceed through 6 basic tenets of applying CT in their lives:

1. state, explain, and clarify the question(s)

2. think through the question(s) from multiple points of view, expressing their own priors using logical thinking

3. gather, organize, assimilate information and data

4. identify assumptions, shortcomings, and implications of the data generation process

5. update priors, both their own priors and consider how other's views might change

6. explain and apply what they learn, connecting what they just learned to other economic concepts, learnings from another course, and/or their everyday life

These might be viewed as a daunting classroom task, but with a proper playbook I have learned that integrating CT skills throughout the course is neither onerous nor redundant, indeed it livens up the classroom and brings economics to life. In this spirit, I envision a set of necessary conditions in Principles of Economics 101 that help to accomplish the 6 basic tenets naturally:

A. Early discussion of simple empirical tools; distinction between correlation and causation; and, provide examples throughout the course that distinguish causation and correlation 
B. Theory of mind should be reinforced (I cannot think of a better place than Game Theory); briefly introduce psychological biases that prevent the student from becoming Adept

C. Because CT development is a social activity, both lab and field experiments should be used as a pedagogical device to promote CT (see Harrison and List, 2004; List, 2014)

D. Connect theory to empiricism and highlight potential shortcomings of both without undoing the major insights

One approach to putting these 4 necessary conditions into action and drawing out the 6 basic CT tenets can be illustrated in my own Economics textbook with Daron Acemoglu and David Laibson (Acemoglu et al., 2020). A key element of our book is the Evidence-Based Economics (EBE) features, which highlight how economists use data to answer the question posed in the opening paragraph of each chapter. The EBEs use actual data from field experiments, lab experiments, naturally occurring data, or government data, while highlighting major concepts in the chapter. These features let students get a real look at economics as it plays out in the world around them. Examples include such questions as "How would an ethanol subsidy affect ethanol producers" (Chapter 6, Sellers and Incentives) and "Is there value in putting yourself into someone else's shoes" (Chapter 13, Game Theory)?

In the conclusion of each $\mathrm{EBE}$ is where one can see how these CT elements come together. Figures $2 \mathrm{a}$ and $2 \mathrm{~b}$ provide two such examples that set the 6 basic tenets in motion. As Figure $2 \mathrm{a}$ shows, the EBE summary in Chapter 6 begins with a succinct summary of the question. The theoretical answer cues thinking about the question from two points of view, which represents an important distinction theoretically. The generated data come both from an experiment and naturally-occurring data. Then, the results are appropriately caveated by generalization considerations (lab data) and causality concerns (naturally-occurring data). Together, this EBE has so far provided insights into the first 4 basic tenets. After which, I have learned that subsequent discussion of the EBE naturally brings out tenets 5 and 6.

Figure 2b, which comes from Acemoglu et al. (2020) Chapter 13, illustrates the same features but brings to bear theory of mind considerations directly by asking if there is value in putting yourself in someone else's shoes. The answer is an unequivocal yes, but the answer also reveals that people have a hard time with theory of mind, it does not come naturally to fast thinkers. In fact, the answer reveals that it takes several rounds of experience to become familiar with the 
strategic environment and begin to think more slowly. I have found that this example readily brings out tenets 5 and 6 during the discussion, highlighting the great import of theory of mind.

Figure 2a: EBE Example from Acemoglu et al. (2020) Chapter 6

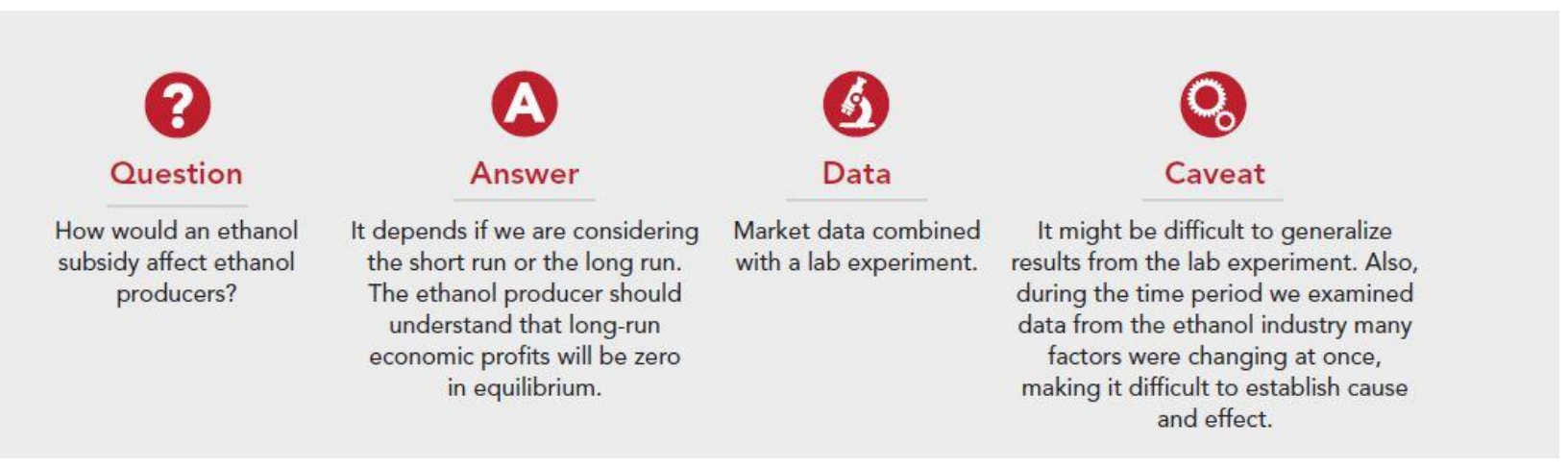

Figure 2b: EBE Example from Acemoglu et al. (2020) Chapter 13

Question
$\begin{gathered}\text { Is there value in putting } \\ \text { yourself into someone else's } \\ \text { shoes? }\end{gathered}$
$\begin{gathered}\text { In many economic situa- } \\ \text { tions, there is great value. }\end{gathered}$ $\begin{gathered}\begin{array}{c}\text { Many features can influence } \\ \text { how people behave and } \\ \text { the experiment focuses on } \\ \text { a few of those reasons for } \\ \text { cooperation. }\end{array} \\ \text { on Trust. }\end{gathered}$

\section{Epilogue}

Teaching Principles of Economics is difficult because at once the student must learn

i) a new language (economese),

ii) to apply abstract and conceptual reasoning,

iii) to apply mathematical concepts that they memorized mechanically in High School,

iv) to become competent at drawing, manipulating, and understanding graphs/figures, and

v) to use logic in places that they have never attempted to apply such concepts 
Pedagogically, we should understand the CT level of students - they are, for the most part, "fast thinkers" - and be surgically precise when inserting CT ideas during the course, complementing rather than replacing traditional learnings. This follows the notion of how we should incorporate new concepts, such as behavioral economics, which David Laibson and I wrote about (Laibson and List, 2015) some time ago:

"There are many great ways to incorporate behavioral economics in a first-year undergraduate economics class-i.e., the course that is typically called "Principles of Economics." Our preferred approach integrates behavioral economics throughout the course. With the integrated approach, behavioral content plays a role in many of the chapters of the principles of economics curriculum, including chapters on optimization, equilibrium, game theory, intertemporal choice, probability and risk, social preferences, household finance, the labor market, financial intermediation, monetary policy, economic fluctuations, and financial crises. We prefer the integrated approach because it enables the behavioral insights to show up where they are conceptually most relevant."

The exact same reasoning holds for how we insert CT and enhance CT skill formation. It all starts with a cohesive model that can provide clarity that permits us to both define the problem as well as add CT to our pedagogy where it is conceptually most appropriate This is important because the student left on their own pursuits will generally choose the route that is immediately easy, that which is comfortable, and that which serves their own selfish interests (Elder and Paul, 2010). At the same time, the literature and our own teaching experiences reveal that CT is difficult and oftentimes too complex for the student to navigate alone. For these reasons, it is crucial that we as teachers and educators explore how best to embed CT skills in our own classrooms, giving students the best chance to discover their own "patterns of thinking," and how they can become better, and "slower," thinkers both within and well beyond the walls of our classrooms.

\section{References}

Abrami, Phillip C., et al. "Strategies for Teaching Students to Think Critically: A Meta-Analysis". Review of Educational Research, 85 no. 2 (2015): 275-314

Acemoglu, Daron, David I. Laibson, and John A. List. Economics. 2nd Edition. Boston: Pearson, 2020.

Alevy, Jonathan, Michael Haigh, and John A. List. "Information Cascades: Evidence from a Field Experiment with Financial Market Professionals,” Journal of Finance, 62(1): 151-180. 
Angeli, Charoula, and Nicos Valanides. "Instructional effects on critical thinking: Performance on ill-defined issues." Learning and Instruction 19, no. 4 (2009): 322-334.

Cacioppo, John. T., R.E. Petty, "The need for cognition." Journal of Personality and Social Psychology,(1982), 42(1), 116-131.

Charness, Gary, John A. List, Aldo Rustichini, Anya Samek, and Jeroen Van De Ven. "Theory of mind among disadvantaged children: Evidence from a field experiment." Journal of Economic Behavior \& Organization 166 (2019): 174-194.

Cowell, Jason M., Anya Samek, John List, and Jean Decety. "The curious relation between theory of mind and sharing in preschool age children." PLoS One 10, no. 2 (2015): e0117947.

Elder, Linda, and Richard Paul. "Critical thinking: A stage theory of critical thinking: Part I." Journal of Developmental Education 20, no. 1 (1996): 34.

Elder, Linda, and Richard Paul. "Critical Thinking: Competency Standards Essential for the Cultivation of Intellectual Skills, Part 1." Journal of Developmental Education 34, no. 2 (2010): 38-39.

Fath, Joseph R., et al. "Group treatment of problem-solving deficits in outpatients with traumatic brain injury: A randomised outcome study" Neuropsychological Rehabilitation, 13 no. 4 (2003)

Gneezy Uri and John A. List, "The Why Axis: Hidden motives and the undiscovered economics of everyday life." (2013), Public Affairs Books.

Harrison, Glenn W., and John A. List. 2004. "Field Experiments." Journal of Economic Literature 42 (4): 1009-55.

Holmes, N. G., Carl E. Wieman, and D. A. Bonn. "Teaching critical thinking." Proceedings of the National Academy of Sciences 112, no. 36 (2015): 11199-11204.

Kahneman, Daniel. "Thinking Fast and Slow," (2011), Publisher: Farrar, Straus, and Giroux.

Klaur, Karl Joseph. "Teaching inductive reasoning: some theory and three experimental studies". Learning and Instruction 6 no.1 (1996)

Laibson, David, and John A. List. "Principles of (behavioral) economics." American Economic Review 105, no. 5 (2015): 385-90.

List, John A. A. 2004. "Testing Neoclassical Competitive Theory in Multilateral Decentralized Markets." Journal of Political Economy 112 (5): 1131-56.

List, John A. "Using field experiments to change the template of how we teach economics." The Journal of Economic Education 45, no. 2 (2014): 81-89.

Leighton, Jacqueline P. "Teaching and Assessing Deductive Reasoning Skills". The Journal of Experimental Education 74, no. 2 (2006)

Maslow, Abraham Harold. "A theory of human motivation." Psychological Review 50, no. 4 (1943): 370-396.

Maslow, Abraham. "Motivation and Personality" Harper \& Row Publishers, Inc., New York (1954)

Miri, Barak, Ben-Chaim David, and Zoller Uri. "Purposely teaching for the promotion of higherorder thinking skills: A case of critical thinking." Research in Science Education 37, no. 4 (2007): 353-369.

Siegfried, John and David Colander. "“What does critical thinking mean in teaching economics, the big and little of it" (2021).

Smith, Vernon L. "An Experimental Study of Competitive Market Behavior.” Journal of Political Economy, 70.2 (1962): 111-137. 
Vas, Asha, et al. "Reasoning training in veteran and civilian traumatic brain injury with persistent mild impairment". Neuropsychological Rehabilitation, 26, no. 4 (2016)

Vas, Asha, et al. "Higher-Order Reasoning Training Years After Traumatic Brain Injury in Adults". Journal of Head Trauma Rehabilitation 26 no. 3 (2011). 